\title{
O misticismo na obra de Theo Angelopoulos: um estudo de $A$ eternidade e um dia (1998)
}

\author{
Mysticism in Theo Angelopoulos' Work: \\ A Study of Eternity and a Day (1998) \\ El misticismo en la obra de Theo Angelopoulos: \\ un estudio de La eternidad y un día (1998)
}

Carlos Eduardo Mendes de Araújo Couto (Universidade Federal de Juiz de Fora, Brasil)*

https://doi.org/10.22409/poiesis.v22i37.45525

\begin{abstract}
RESUMO: A obra tardia do cineasta Theodoros Angelopoulos, desenvolvida na década de 1990, possui atributos políticos e humanos já percebidos e decifrados tanto pela crítica quanto pela academia. Todavia, notamos também em seus filmes um aspecto místico ainda não explorado em nenhum desses meios. O objetivo desse artigo é caracterizar a experiência mística em uma determinada produção do realizador grego. Nosso objeto de estudo será a obra $A$ Eternidade e um dia (Mia aioniotita kai mia mera, 1998). Usaremos como suporte teórico autores como Robert Charles Zaehner, Steven Katz, Paul Schrader e Frederico Pieper.
\end{abstract}

PALAVRAS-CHAVE: cinema; misticismo; Angelopoulos

\footnotetext{
* Carlos Eduardo Mendes de Araújo Couto é mestre e doutorando em Artes, Cultura em Linguagens na Universidade Federal de Juiz de Fora. Orcid: https://orcid.org/0000-0002-4843-3548. E-mail: cadumendescouto001@gmail.com.
} 
ABSTRACT: Theodoros Angelopoulos' late work, developed in the 1990s, has political and human attributes already perceived and deciphered by critics and academia. However, we also notice in his films a mystical aspect that has not yet been explored in any of these media. The purpose of this article is to characterize the mystical experience in a particular production by the Greek director. Our object of study will be the work Eternity and a day (Mia aioniotita kai mia mera, 1998). We will use as theoretical support authors like Robert Charles Zaehner, Steven Katz, Paul Schrader and Frederico Pieper.

KEYWORDS: cinema; mysticism; Angelopoulos

RESUMEN: La obra tardía del cineasta Theodoros Angelopoulos, que se desarrolló en la década de 1990, posee atributos políticos y humanos así que los percibieron y los descifraron la crítica y también la academia. Sin embargo, hemos observado también que sus películas presentan un algo de místico que el director no lo ha explorado en ningún de estos medios aún. El objetivo de este artículo es hacer una caracterización de la experiencia mística en una determinada producción del director greco. Nuestro objeto de estudio es la obra La eternidad y un día (Mia aioniotita kai mia mera, 1998). Utilizaremos en el aporte teórico algunos autores como Robert Charles Zaehner, Steven Katz, Paul Schrader y Frederico Pieper.

PALABRAS CLAVE: cine; misticismo; Angelopoulos

Recebido: 24/8/2020; Aprovado: 7/12/2020; Publicado: 2/1/2021.

Citação recomendada:

COUTO, Carlos Eduardo Mendes de Araújo. O misticismo na obra de Theo Angelopoulos: um estudo de A eternidade e um dia (1998). Revista Poiésis, Niterói, v. 22, n. 37, p. 391-406, jan./jun. 2021. [https://doi.org/10.22409/poiesis.v22i37.45525]

\section{(cc) BY-NC-ND}

Este documento é distribuído nos termos da licença Creative Commons Atribuição-NãoComercial 4.0 Internacional (CC-BY-NC) (C) 2021 Carlos Eduardo M. A. Couto

Carlos Eduardo Mendes de Araújo Couto, O misticismo na obra de Theo Angelopoulos... 


\section{O misticismo na obra de Theo Angelopoulos: um estudo de $A$ eternidade e um dia (1998)}

Introdução

As representações imagéticas tornaram-se, principalmente, a temer os ensinamentos ao longo do tempo, instrumentos da variedade de experiências, sentimentos e interesses religiosos dos indivíduos e instituições. Desde o paleolítico, os antigos caçadores esboçaram as mais primitivas formas de arte como expressão religiosa, visando o controle da natureza e dos espíritos dos animais, notadamente nas cavernas de Altamira, na Espanha, e em Lascaux, na França. No medievo, a arte gótica, surgida no norte da França, possuía um caráter didático: ajudava os cristãos a entender e, da Igreja Católica. As pinturas de Giotto di Bondonne (1267-1337) e Giovanni del Biondo (1356-1399) traziam as premissas religiosas da época. Já no século XIX, era da Revolução Industrial, da proliferação das ciências e das técnicas, a arte cinematográfica despontou e se tornou expressão artística típica do século $X X$, refletindo também essa busca do homem pelo sagrado, pelo transcendente, pelo místico e pelo inefável. As articulações entre religião e cinema tornaram-se objeto de estudo de vários crí- 
ticos e pesquisadores que buscavam um aprofundamento teórico sobre esse imbricamento entre campos tão distintos. Ao longo do tempo, construiu-se na academia uma distinção entre os filmes no-tadamente religiosos e aqueles considerados transcendentes, ou seja, de temática secular, mas que apresentam elementos espirituais em sua linguagem. De acordo com Getlein e Gardiner (apud PIEPER 2015, p. 28), filmes religiosos seriam aqueles que apresentam temas e símbolos explicitamente religiosos, como pessoas sagradas, santos, milagres, livros religiosos, sacerdoreligioso deve estar visível de modo explícito, sendo representado por seus aspectos mais perceptíveis. Apresenta-se a religião de uma forma mais tradicional e conservadora, afirmando as interpretações e posições oficiais das instituições religiosas (PIEPER, 2015, p. 28).

Para o roteirista e também teólogo Paul Schrader (1972), filmes considerados transcendentes são aqueles em que o espiritual e o sagrado são mais evocados do que propriamente retratados. Não haveria uma temática claramente religiosa ou mesmo componentes religiosos em cena.

Há uma necessidade de apresentar e debater questões metafísicas, místicas e transcendentes através da própria narrativa ou de outros elementos da linguagem cinematográfica, como a iluminação, a cenografia, a montagem e a música.

\section{Theo Angelopoulos}

Um dos cineastas cuja obra se encaixa nos atributos do cinema transcendental é o grego Theodoros Angelopoulos. Nascido em Atenas, em 1936, veio a falecer na cidade grega de Pireu, em 2012, enquanto realizava seu último filme. Sua obra faz uma abordagem poética da realidade da península balcânica ao longo do século $X X$, utilizando uma variedade de alegorias e referências daquela parte do mundo, como a mitologia helênica, a literatura épica e a música tradicional grega.

Há um consenso entre os estudos acadêmicos sobre a obra de Angelopoulos: esta pode ser dividida em dois períodos. O primeiro consiste em filmes cujos protagonistas são coletivos, partidos ou grupos de pessoas. A segunda fase marca um movimento em direção ao indivíduo, explorando questões 
pessoais e convidando a uma maior identificação emocional. Em ambas as etapas, o pano de fundo é o mesmo: a história dos Bálcãs no século $X X$, o sofrimento dessa região com os conflitos mundiais, a ascensão fascista, a guerra civil, a pobreza dos países, as repressões sociais e morais e como todas essas questões afetaram seus habitantes e suas relações interpessoais.

Para David Bordwell (apud HORTON, 1997), a diferença entre os dois períodos é evidente. A primeira etapa vai de Reconstituição (Anaparastasi, 1970) a Alexandre, o Grande (Megaleksandros, 1980). A segunda se inicia com Viagem à Citera (Taxidi sta Kythira, 1983) e termina com A poeira do tempo (The Dust of Time, 2008). Enquanto que nos primeiros anos as obras têm fins claramente políticos e os filmes são ideologicamente comprometidos, nos anos seguintes "delineiam crises individuais e pessoais" (apud HORTON, 1997, p. 24). Contudo, Bordwell considera a diferença apenas uma questão de mudança de ênfase, pois até mesmo os filmes recentes abordam questões políticas concretas: a morte do marxismo, o fluxo desesperado de populações europeias através das fronteiras, a possibilidade de políticas nacionais baseadas na honra. Como ele sugere em sua conclusão, "na carreira de Angelopoulos, o peso da ênfase mudou, mas ele sempre combinou a crítica política com um tom pessimista". (apud HORTON, 1997, p. 24, tradução nossa)

Fredric Jameson também percebe a mesma distinção entre os dois períodos (apud HORTON, 1997). O autor enfatiza que, em seus primeiros filmes, Angelopoulos inova ao desenvolver narrativas coletivas e ao projetar os destinos de um grupo de personagens. Salienta ainda a singularidade do estilo de Angelopoulos, que consegue "dar destaque a algo irrepresentável, o coletivo" (apud HORTON, 1997, p. 86). Para Jameson, o início da "nova" ou "tardia" fase de Angelopoulos, voltada ao indivíduo e seus dilemas, se inicia com Viagem à Citera (Taxidi sta Kythira, 1983) e termina com A poeira do tempo (The dust of time, 2008). Todavia, ele considera o período posterior, direcionado à experiência de um protagonista e suas questões pessoais, formalmente regressivo, com a preponde-rância do tradicional individualismo burguês na arte cinematográfica. 
Todavia, sob outro olhar, notamos que determinados trabalhos realizados na última década de 1990 não se restringem apenas aos dilemas humanos em um contexto sócio-político extremamente problemático, apresentando um caráter que entendemos como místico, mas um misticismo secularizado, longe das práticas e interpretações religiosas tradicionais. Ora, em sua narrativa principal, seus protagonistas empreendem jornadas pelos Balcãs, uma região com problemas políticos e humanitários. Devido às dificuldades enfrentadas na viagem, os indivíduos passam por experiências místicas relacionadas à transitoriedade de suas vidas e à descoberta de uma dimensão atemporal. Através de uma ruptura espaço-temporal acessam seus afetos e eventos do passado, que são conectados, sobrepostos e ligados às imagens e aos sons da atualidade de forma lírica, ressignificando seu presente.

A partir da constatação desse misticismo secularizado em determinados filmes da fase tardia de Angelopoulos, buscaremos neste artigo caracterizar a experiência mística nos trabalhos do cineasta grego. Os fenômenos apresentados nesses filmes se encaixam em uma epistemologia contem- porânea da mística, principalmente a do pós-guerra, próximos das ideias de Robert Charles Zaehner e Steven Katz. Como amostra, escolhemos Eternidade e um dia (Mia aioniotita kai mia mera, 1998), justamente por ser a obra que melhor demonstra esse lado místico da obra tardia de Angelopoulos.

\section{R. C. Zaehner e a experiência mística natural}

Robert Charles Zaehner defendeu a tese da "experiência mística natural que pode ocorrer a qualquer pessoa, seja qual for a sua fé religiosa ou a falta dela e qualquer que seja a vida moral, imoral ou amoral ele possa estar vivendo na época" (1961, p. 12). Rejeitou repetidamente a ideia da uma unidade mística de todas as religiões. $\mathrm{O}$ autor recusa a ideia à qual as vivências místicas de diferentes religiões, as experiências místicas naturais, o uso de drogas psicodélicas e distúrbios como a esquizofrenia sejam essencialmente o mesmo fenômeno.

Zaehner distingue então duas categorias de experiência mística. Uma delas é a sagrada ou religiosa, que pode ser teísta - ou seja, 
a crença na existência de um ou mais deuses. Essa categoria teísta inclui a maioria das formas de misticismo judaico, cristão e islâmico e exemplos hindus ocasionais - ou monista - quando a alma universal e alma individual são uma só e a mesma coisa. O autor sugere que um exemplo de teísmo seria o de São João da Cruz, enquanto o monismo pode ser visto no não-dualismo do Vedanta ${ }^{1}$.

A outra experiência mística seria a profana ou natural, que pode acontecer através do uso de drogas, devido a patologias ou mesmo subitamente, sem qualquer preparação de ordem ascética e independente de formação religiosa. Há uma identificação do sujeito "com a totalidade da natureza", na qual o indivíduo acessa outros espaços em tempos distintos e singulares. Nas palavras do próprio Zaehner:

\footnotetext{
Em todos os casos, a pessoa que tem a experiência parece estar convencida de que o que ela experimenta, longe de ser uma ilusão, é ao contrário algo muito mais real do que aquilo que ela experimenta normalmente por meio de seus cinco sentidos ou o que ela pensa com sua mente finita. Isso significa, em sua mais alta expressão, transcender o tempo e 0
}

espaço na qual um modo de ser infinito é realmente experimentado. (ZAEHNER, 1961, p. 82, tradução nossa).

Outra forma de experiência natural é aquela encontrada nas obras de Marcel Proust, Arthur Rimbaud e John Custance. Todavia, para nosso artigo, iremos nos ater à obra máxima de Proust, uma vez que as experiências ocorridas no texto proustiano se aproximam daquelas encenadas no filme de Angelopoulos.

A extensa novela de Proust Em busca do tempo perdido retrata a sociedade francesa do fin-de-siècle até o início da I Guerra Mundial. O protagonista Marcel narra sua vida na alta sociedade francesa, seu desejo em tornar-se escritor, a luta pelo reconhecimento social e a busca pela realização amorosa. O que mais chama atenção no livro são as viagens do personagem principal ao passado através de sua memória involuntária, ativada graças a pequenas distrações, como um pequeno doce, a madeleine ${ }^{2}$, um guardanapo ou uma pedra no chão.

Segundo Zaehner, a experiência mística chega para o protagonista sem qualquer 
exercício ou conexão religiosa prévia. São elementos simples do cotidiano, já apontados no parágrafo acima, que forneceram ao personagem a visão de um mundo atemporal, para além da transitoriedade da vida e da realidade concreta. Ora, Marcel percebe que sua essência não está limitada às mazelas da vida normal e cronológica.

Na obra proustiana há a distinção de dois selfs. Um deles conectado ao cotidiano, que sofre melancolicamente a impermanência de todas as coisas. Outro, que atua em sua própria memória, reatualizando o próprio passado que parece disputar com o presente um dentro da alma. No entanto, como sugere Zaehner (1961, p. 93), isso claramente não significava qualquer expansão do ego, mas sim uma supressão daquela entidade cansada.

Zaehner (1961, p. 93-94) salienta então que na experiência proustiana, os elementos comuns do passado e do presente se fundem em um lugar que parece estar fora do tempo e que participa da natureza da eternidade. Proust comunica a fluidez da realidade em constante mudança. O protagonista dos romances experimenta uma completa integração com toda a sua vida passada, fora do espaço-tempo cotidiano. Os momentos mágicos de integração com o passado, ou o reencontro do tempo perdido, revelavam um segundo "eu" dentro dele, cuja operação estava fora do tempo cronológico.

\section{Steven Katz e o "contextualismo"}

De acordo com abordagem contextual defendida por Steven Katz, as experiências são eventos particulares, predeterminadas por práticas religiosas específicas. Diferentes contextos religiosos produzem, assim, diferentes tipos de experiências que não podem ser equiparadas umas às outras. Assim, o indivíduo tende a experimentar as vivências propostas por sua tradição. Katz insiste que os místicos cristãos experimentam um Jesus cristão; os sufis, um Alá muçulmano e os místicos budistas, um Buda.

A análise desse aspecto "mediado" é necessária na investigação do misticismo. De fato, para compreendermos a experiência mística não devemos apenas estudar os relatórios do místico após o fenômeno, mas reconhecer e estudar os conceitos que o sujeito traz e que moldam toda sua experiência. 
De acordo com Katz (1978), as descrições da experiência mística com frases escolhidas, termos e adjetivos de significado vazio, fora de seu contexto histórico, social e religioso, não fornecem meios para sua comparação, mas expõem os fundamentos de inteligibilidade. Toda essa semântica torna-se um problema que aflige as tentativas que vários estudiosos fazem para fornecer uma descrição comum da experiência mística. O fato é que essas listas de palavras e elementos supostamente comuns não reduzem a variedade de experiências tão díspares a um fenômeno específico e são de pouca ajuda na compreensão do fenômeno, pois são tão amplos que cabem em qualquer descrição fenomenológica do evento místico.

De fato, há uma diversidade de experiências que podem ser consideradas como místicas, algumas conectadas com um aspecto religioso, com o sagrado, deuses e santos; outras não, de natureza profana, causadas pelo uso de drogas alucinógenas ou ocasionadas por algum tipo de emoção, que ocorrem naturalmente e vivenciadas em um espaço-tempo distinto.
Além de tratar da questão do fenômeno propriamente dito, Katz entra no âmbito do relato e da expressividade da experiência mística (1992). Para o intelectual, o indivíduo descreve sua experiência com o mesmo conteúdo intelectual e estrutura linguística que o fez experimentar o fenômeno. Há, de acordo com Katz, uma relação direta entre a experiência e o relato da vivência, isto é, os místicos descrevem exatamente aquilo que experimentam, o que nega a natureza inefável do fenômeno. O fenômeno pode então ser descrito racionalmente. A esse respeito, Katz observa que

\section{[...] ao contrário de suas próprias declarações sinceras a respeito da inefabilidade, a lógica estrutural de tais teorias necessariamente nos diz mais do que os defensores das apofasia re- conhecem. E esse fato deve ser tomado como paradigmático dos sistemas místicos univer- salmente; [...] a realidade é outra. Ou seja, os místicos revelam, ainda que não intencional- mente, mais da "verdade" que eles conhece- ram na linguagem do que sugeririam suas ne- gações explícitas de significado e conteúdo. (KATZ, 1992, p. 25, tradução nossa).}

Katz afirma a importância da linguagem para a experiência mística (1992). O autor 
analisa práticas de diferentes tradições místicas, como a Cabala, Sufismo e Budismo, para demonstrar a relevância da linguagem para o fenômeno místico. A experiência é condicionada por influências linguísticas anteriores e está em conformidade com um padrão cognitivo preexistente. Para Katz, a linguagem serve para induzir avanços da consciência, sendo fundamental para a travessia do caminho do místico, para o movimento da consciência A para a consciência B. Ao analisar determinadas tradições místicas e relacioná-las com suas respectivas linguagens - cabala com hebraico e hindu-ísmo com sânscrito , Katz aponta como estas grandes tradições encontram maneiras ricas e sutis de transmitir aspectos primordiais de sua verdade através da linguagem e como esse léxico está frequentemente ligado ao divino.

Acreditamos, todavia, que a linguagem extrapole apenas o contexto religioso e possa ser utilizada de forma secularizada, em nossa realidade concreta, ou em formas artísticas como a poesia. As palavras podem funcionar como condutores a fim de alcançar determinados estados místicos. Nesse caso, as palavras têm poder locomotor, transportam o indivíduo de uma determinada realidade cotidiana e concreta a outra, atemporal e elevada.

\section{0 misticismo em Theo Angelopoulos:} a análise de Eternidade e um dia (Mia aioniotita kai mia mera, 1998)

Eternidade e um dia conta a história de Alexander, interpretado pelo ator alemão Bruno Ganz, um consagrado escritor e tradutor grego, que está doente e perto da morte. Após se despedir da filha, ajuda um menino albanês, o jovem Ahilleas Skevis, a fugir de traficantes de crianças. Alexander decide então levar o menino até sua aldeia na Albânia. Durante a viagem passa por uma série de experiências místicas que o levam à sua antiga residência e ao contato com sua falecida esposa Anna, a atriz francesa Isabelle Renauld.

As primeiras imagens do filme apresentam uma mansão. Corte para o interior do quarto. Um longo plano sequência acompanha Alexander, ainda criança, saindo de sua casa correndo para dentro do mar com seus jovens amigos, enquanto as palavras do poeta e filósofo Heráclito de Éfeso, narradas em off, anunciam a importância da 
cultura, da mitologia e da língua grega para Angelopoulos e um tema constante nesse filme, o tempo com suas transições, memórias e ausências: "O tempo é uma criança que brinca com pedras na praia". O tempo é filho do deus Cronos e, como uma entidade alegórica pode ser entendida como o tempo linear ou o tempo eterno e uma criança, com sua inocência e ingenuidade, pode brincar com o tempo, retornando ao passado, avançando ao futuro, criando atemporalidades. Alexander, o protagonista, também modificará o tempo e ressignificará seu presente.

Uma sobreposição de imagens do mar traz a sequência de volta para a Grécia de 1998. Alexander sentado em sua cadeira, visivelmente doente, acompanhado de uma enfermeira que lhe informa que precisa ir ao hospital se internar. "Ainda sinto o gosto do sal", anuncia nosso protagonista, uma metáfora, já anunciando intenção de fugir da linearidade do tempo histórico, relembrando sua infância, um tempo seguro e inocente quando nadava no mar com seus amigos e sua família.

No caminho para o hospital, Alexander visita sua filha e conversam sobre sua mãe.
A filha então the entrega cartas deixadas por Anna, esposa e mãe. Alexander começa a leitura e, emocionado, se dirige à varanda. As cartas são apelos à atenção do esposo, sempre tão distante dela e de todos. Ao atravessar as cortinas, tem sua primeira experiência mística. Há uma rup-tura espaço-temporal e Alexander é deslocado para sua antiga casa, com sua falecida esposa. Conversam sobre o vestido, as visitas e a gravidez. Um corte seco. Carros antigos denotam o tempo passado. Os convidados chegam e adentram a casa. A voz em off de sua esposa trata do amor entre eles e se alterna com as conversas de teor político dos personagens.

Foram as palavras de Anna que ocasionaram o fenômeno místico, que está longe de ser apenas uma lembrança, uma vez que é o Alexander de hoje, velho e doente, que interage com sua esposa. Não há qualquer referência religiosa, nenhuma ascese prévia, o evento simplesmente acontece, uma típica experiência mística natural, como descrita como R. C. Zaehner. O conteúdo da experiência é moldado pela memória e pela cultura pessoal de Alexander, sua vida com Anne, suas amizades, o contexto político e social. 
Alexander sai da casa de sua filha e se dirige ao hospital. No caminho, pelas ruas de uma Tessalonika caótica e cinzenta, ajuda uma criança que limpa seu carro no sinal de trânsito a fugir de seus perseguidores. Alexander segue o menino e percebe que ele volta a cair prisioneiro dos criminosos que o levam, dentro de um pequeno caminhão, para um local onde há adoções ilegais e tráfico de crianças. Alexander resgata o jovem e decide levá-lo de volta à sua aldeia na Albânia.

Em estado terminal e responsável por uma criança, a jornada de Alexandre ao interior do país torna-se a metáfora de uma viagem interior. Alexander realiza uma análise de si mesmo, confrontado seus infernos pessoais, suas dores e medos, à procura de um passado, conectando-se com os espíritos que povoaram sua vida, como se buscasse o contato com familiares com quem irá se encontrar em um tempo próximo.

Alexander leva seu pequeno amigo de volta à Albânia, mas param diante da fronteira congelada, uma cerca que parece cheia de corpos, como espantalhos pendurados do arame farpado. Os dois se olham por segundos. Um guarda se aproxima e eles fogem.
A partir deste momento, seus destinos se unem: não há mais retorno possível. O filme conta agora a história de dois heróis solitários, arrancados de sua família, de seu contexto social e até mesmo geográfico.

Na jornada pelo interior da Grécia, Alexander transita livremente entre diferentes momentos de sua história pessoal, intercalando-a com a exuberante cultura grega. Chama a nossa atenção outra quebra do espaço-tempo no qual os protagonistas observam o poeta grego do século XIX, Dyonisios Solomos (Fabrizio Bentivoglio), vestido com trajes da era romântica em uma antiga ruína grega.

De fato, a experiência mística é condicionada por influências linguísticas e também está em conformidade com determinados padrões culturais anteriores. A rica cultura grega, representada nessa sequência por Solomos, fornece o contexto cultural e cognitivo para o evento místico de Alexander e do menino. As ruínas da construção representam as ruínas de nosso interior, nosso castelo despedaçado e as palavras de uma poesia podem funcionar como um fluxo, um mantra, a fim de conduzir os indivíduos a determinados estados de contemplação ou místicos. 
De volta a Tessalonika, na larga avenida que beira o mar, Alexander encontra com seu médico e conversam sobre o estado de saúde terminal do protagonista. Há uma dose de melancolia na sequência. O menino sai de cena e Alexander se dirige em direção ao mar, sussurrando palavras em desvario, chamando por sua esposa Anna. Outra ruptura acontece, certamente causada pelo excesso de emoções, e Alexander se encontra em um barco, com pessoas cantando e dançando. Ele se dirige ao final da embarcação onde estão Anna e sua mãe. Alexander beija carinhosamente sua mãe e conversa com Anna, que reclama sua ausência em todos os anos do casamento. Corte. Todos agora se encontram em uma ilha grega, vestidos com roupas claras, com exceção de Alexander que ainda veste suas roupas pretas e puídas de sua própria realidade. Como um ato contínuo, repetição de toda uma vida, Alexander se dirige para o lado oposto de Anna que parece desistir do relacionamento e se di-rige ao mar. Do alto de um penhasco, Alexander acena para um barco, como se estivesse se despedindo da própria vida. Alexander, agora sozinho, após deixar seu jovem amigo no porto onde embarcaria em um navio para a Itália, se dirige ao centro de Tessalonika.
Alexander, agora sozinho após deixar seu jovem amigo em um porto, deve escolher entre o hospital ou sua antiga casa, aquela que morou com Anna e sua família. A escoIha recai na segunda opção. A casa, vazia, não guarda nenhum resquício do conforto e beleza anteriores. Curiosamente, ele entra no mesmo quarto com varanda para a praia onde estava no início do filme, mostrando a circularidade do tempo. A varanda se abre: seus amigos, sua família e sua falecida Anna dançam na praia. Alexander se aproxima e dança com eles. As pessoas abandonam a praia vagarosamente deixando apenas o casal em cena. "PergunteiIhe um dia: quanto tempo o amanhã demora para chegar? E você me respondeu: Uma eternidade e um dia". Anna sai de cena. Alexander está só: "Minha passagem para o outro lado hoje à noite, com palavras, a trouxe de volta. Você está aqui. E tudo é verdade, esperando, pela verdade". Alexander transcende espaço e tempo para ficar com Anna e sua família. Todas as experiências místicas anteriores, como rupturas no templo cronológico, naturais e sem qualquer conotação religiosa, forneceram momentos para Alexander corrigir sua ausência, reconstruir seus contatos e ressignificar seu presente, preparando o terreno 
para o epílogo, quando estariam todos juntos. A cultura, a mitologia, a poesia grega e a própria história pessoal do escritor forneceram o suporte cognitivo para todos os fenômenos espirituais ocorridos na jornada de Alexander e as palavras funcionaram como um mantra para a Eternidade e um dia.

\section{Conclusão}

Após apresentarmos os principais pressupostos das abordagens de Zaehner e Katz, que nos fornecem o fundamento teórico, devemos agora estabelecer os aspectos da mística na obra tardia de Theo Angelopoulos. De fato, a mística na obra do cineasta grego pode ser caracterizada como uma confluência entre determinadas ideias de Zaehner e Katz.

As formas de experiência mística desenvolvidas nas obras cinematográficas de Angelopoulos, notadamente em Eternidade e um dia, se afastam dos fenômenos que ocorrem no âmbito das tradições religiosas, com suas práticas oracionais, meditativas e teúrgicas, e se encaixam no modelo de fenômeno natural, secularizado e profano, descrito por Zaehner, nos quais os indivíduos, em seus estados místicos, transcendem o tempo e o espaço, mas experimentam algo próximo de sua realidade e de sua vida concreta.

E ainda que Katz restrinja sua teoria sobre a mediação da experiência mística apenas às formas religiosas dos fenômenos, não desenvolvendo um estudo pertinente sobre as experiências naturais ou estados alterados de consciência, consideramos que os fenômenos místicos naturais e dessacralizados, que ocorrem com os personagens de Angelopoulos, são igualmente mediados e determinados por condicionamento, por sua condição social e histórica. Ora, de acordo com Katz, os fenômenos são o reflexo das formações pessoais dos sujeitos místicos, de suas histórias de vida e de suas inserções em determinados contextos, no caso a região balcânica com seus problemas políticos e humanitários, o fim do socialismo e a guerra da Bósnia, a modernidade e a globalização.

Assim como a linguagem, especialmente a religiosa, é fundamental para o condicionamento do fenômeno místico, como nos afirma Katz, a língua grega é importante para o desenvolvimento da experiência nos 
filmes de Angelopoulos. Ela se torna fundamental para a travessia do caminho do místico, para a condução de uma realidade concreta, cronológica, para a transcendência. As expressões em grego fornecem as pistas, dirigem a atenção dos espectadores para o estado místico.

\section{Notas}

1 Tradição religiosa indiana.

2 Pequenos doces que molhados no chá faziam o protagonista Marcel se lembrar de seu passado.

\section{Referências}

ANDREW, Geoff. Theo Angelopoulos: The Sweep of History. Sight and Sound, 2012. Disponível em http://old.bfi.org.uk/ sightandsound/feature/49816. Acesso em 25/11/2019.

BIRD, Michael. Film a Hierophany. In: MAY, John R. ; BIRD, Michael. Religion in Film. Knoxville: The University of Tennessee Press, 1998, p. 3-22.

BRYANT, Darrol. Cinema, Religion and Popular Culture. In: MAY, John R. ; BIRD, Michael. Religion in Film. Knoxville: The University of Tennessee Press, 1998, p. 104-114.

CABRAL, Jimmy Sudário; BINGEMER, Maria Clara (Org.). Finitude e Mistério. Mística e literatura moderna. Rio de Janeiro: PUC-Rio; Mauad, 2014

CIMENT, Michel. The State of Cinema. Unspoken Cinema, 2003. Disponível em http://unspokencinema.blogspot.com/2006/10/state-of-cinema-m-ciment.html. Acesso em 10/12/2018.

FLANAGAN, Matthew. Bakhtin and the Movies. New Ways of Understanding Hollywood Film. Londres: Palgrave Macmilln, 2009.

FLANAGAN, Matthew. Towards an Aesthetic of Slow in Contemporary Cinema. 
16:9, nov. 2008. Disponível em http://www.16-9.dk/2008-11/side 11_inenglish.html. Acesso em 10/12/2018.

HORTON, Andrew. The Films of Theo Angelopoulos: A Cinema of Contemplation. Princeton: Princeton University Press, 1997.

HORTON, Andrew. The Last Modernist: The Films of Theo Angelopoulos. Trowbridge: Flicks Books, 1997.

KATZ, Steven. Mysticism and Philosophical Analysis. Nova York: Oxford University Press, 1978.

KATZ, Steven. Mysticism and Religious Traditions. Nova York: Oxford University Press, 1983.

KATZ, Steven. Mysticism and Language. Nova York: Oxford University Press, 1992.

KATZ, Steven. Mystical Speech and Mystical Meaning. Nova York: Oxford University Press, 1992a.

KOUTSOURAKIS, Angelo \& STEVEN, Mark. The Cinema of Theo Angelopoulos. Edinburgo: Edinburgh University Press, 2015.

ORICHIO, Luiz Zanin. O cinema humanista de Theo Angelopoulos. O Estado de São Paulo, 26/1/2012. Caderno de Cultura. Disponível em https://cultura.estadao.com.br/blogs/ luiz-zanin/o-cinema- humanista-de-theo-angelopoulos/. Acesso em 20/4/2019.

PIEPER, Frederico. Religião e Cinema. São Paulo: Fonte Editorial, 2015.

PROUST, Marcel. No caminho de Swann. Tradução de Mário Quintana. São Paulo: Globo, 2006. (Em busca do tempo perdido, v. 1).

SCHRADER, Paul. Transcendental Style in Film: Ozu, Bresson, Dreyer. Berkeley. University of California Press, 1972.

VANOYE, Francis; GOLLIOT-LÉTÉ, A. Ensaio sobre a Análise Fílmica. Campinas: Papirus, 1994.

ZAEHNER, Robert Charles. Mysticism Sacred and Profane. Nova York: Oxford University Press, 1961.

\section{Filmografia}

A Eternidade e um dia. Direção: Theo Angelopoulos. São Paulo: Versátil Home Vídeo, 1998. 132 min., VHS, som, cor, legendado (material digitalizado). 